\title{
Zoneamento agroclimático da palma forrageira (Opuntia sp.) para o estado da Paraíba
}

\author{
Bergson G. Bezerra ${ }^{1}$, Jucilene S. Araújo ${ }^{2}$, Daniel D. Pereira ${ }^{3}$, Gustavo Q. Laurentino ${ }^{4} \&$ Lindenberg L. da Silva $^{5}$
}

${ }^{1}$ PPGCC/UFRN. Natal, RN. E-mail: bergson@ccet.ufrn.br (Autor correspondente)

${ }^{2}$ MCTI/INSA. Campina Grande, PB. E-mail: jucilenearaujo@insa.gov.br

${ }^{3}$ CCA/UFPB. Areia, PB. E-mail: danielduartepereira@hotmail.com

${ }^{4}$ MCTI/INSA. Campina Grande, PB. E-mail: gustavoqueir@hotmail.com

${ }^{5}$ MCTI/INSA. Campina Grande, PB. E-mail: begapb@gmail.com

\section{Palavras-chave:}

climatologia

balanço hídrico climático

indicadores climáticos

precipitação

\begin{abstract}
R E S U M O
A palma forrageira tornou-se, ao longo dos anos, uma importante alternativa forrageira no semiárido brasileiro $(\mathrm{SAB})$ principalmente em longos períodos de estiagens. Apesar de sua magnitude para a agropecuária, seu cultivo tem dispensando tratos culturais básicos e embasamento técnico-científico quanto às suas exigências climáticas. Assim, o principal objetivo deste estudo foi elaborar o zoneamento agroclimático da cultura da palma forrageira (Opuntia sp.) para o estado da Paraíba. O zoneamento agroclimático da palma forrageira foi elaborado com base nos indicadores climáticos delineados na literatura e nos dados climatológicos de precipitação e temperatura (média, máxima e mínima) de 97 localidades do estado da Paraíba. De acordo com os resultados obtidos, a mesorregião da Borborema é a que apresenta as condições climáticas mais favoráveis para o cultivo da palma forrageira. As mesorregiões do Agreste, Sertão e a parte do Litoral, são aptas porém com restrições. No entanto, recomenda-se o cultivo da palma forrageira em todo o território do estado da Paraíba, exceto para a parte costeira da mesorregião do Litoral e região em torno de Areia. Em ambos os casos a inaptidão ocorre em função do excesso de precipitação.
\end{abstract}

Key words:

climatology

water balance

climate indicators

precipitation

\section{Agroclimatic zoning of cactus pear (Opuntia sp.) for the Paraíba state}

\begin{abstract}
A B S T R A C T
The cactus pear has become over the years an important forage alternative for brazilian semiarid region, especially during long periods of drought. Despite its importance for agriculture, its cultivation has dispensed basic crop practices and fundamentals technical-scientific basis about its climatic requirements. Thus, the main objective of this study was to elaborate the agroclimatic zoning of cactus pear (Opuntia sp.) for the state of Paraíba. The agroclimatic zoning of cactus pear was based on climatic indicators outlined in the literature and climatological data of precipitation and temperature (mean, maximum, and minimum) from 97 locations in the state of Paraíba. According to the results, the region of 'Borborema' is the most favorable for the cultivation of cactus pear. The regions of 'Agreste', 'Sertão', and coastal part of Litoral may be used but with restrictions. However, the cultivation of cactus pear is recommended throughout the state of Paraíba, except the coastal part of the Litoral and the region around Areia. In both cases, the inability is due to excessive precipitation.
\end{abstract}

\section{INTRODUÇÃo}

A palma forrageira (Opintia sp.) é um membro da família das Cactáceas, cultivada em todo o mundo, exceto na Antártica, em mais de 1.000 .000 ha principalmente para a produção de frutas e forragem, além do uso como planta ornamental (Reyes-Agüero et al., 2006; Cardador-Martinez et al., 2011). De acordo com Yahia \& Mondragon-Jacobo (2011) a evolução comercial do seu fruto durante a segunda metade do século XX tornou a palma forrageira uma fruteira emergente, conquistando espaços nos mercados consumidores dos EUA e da Europa.

Além da alimentação humana (frutas frescas e secas, sucos etc.) e animal (forragem), a palma forrageira possui um vasto potencial para usos diversos, tais como matéria-prima para a produção de biocombustíveis, cosméticos, adesivos, colas, corantes, antitranspirantes, além de usos medicinais. Seu potencial no uso medicinal está relacionado ao fato de seus frutos serem fontes naturais de betalaínas antioxidantes (Gentile et al., 2004; Tesoriere et al., 2004).

A palma forrageira é bem adaptada às condições semiáridas suportando longos períodos de estiagem. Esta boa adaptabilidade é atribuída, sobremaneira, à sua fisiologia caracterizada pelo processo fotossintético denominado Metabolismo Ácido das Crassuláceas (CAM, sigla do termo em inglês Crassulasean Acid Metabolism) (Snyman, 2006a). As plantas que assimilam o $\mathrm{CO}_{2}$ através do sistema CAM, desenvolveram um mecanismo que fecham os estômatos durante o dia, de modo a evitar a perda excessiva de água pelo processo de transpiração e assim manter 
a hidratação dos tecidos (Taiz \& Zeiger, 2004). Este mecanismo fotossintético diferenciado foi decisivo para a adaptação desta cactácea às condições semiáridas, que lhes conferem uma eficiência de uso da água na faixa de 100 a $150 \mathrm{~kg}$ de água por $\mathrm{kg}$ de matéria seca, o que a torna seis vezes mais eficiente que as leguminosas e quase três vezes mais eficiente que as gramíneas (Felker et al., 2005; Santos et al., 2006).

Embora possua uma reconhecida gama de potencialidades, conforme apresentada anteriormente, a palma forrageira tem sido cultivada no $\mathrm{SAB}$ quase exclusivamente para a produção de forragem (Santos et al., 2001; Araújo et al., 2005; Pinto et al., 2011) e se tornou, ao longo das décadas, uma das principais alternativas para alimentação dos rebanhos, sobretudo em longos períodos de estiagem, quando as pastagens nativas e outras forrageiras, tais como as gramíneas e leguminosas de elevada exigência hídrica, estão sob fortes condições de estresse hídrico. Neste sentido, a palma forrageira é considerada uma importante aliada na sustentabilidade e na redução da vulnerabilidade das atividades agropecuárias no SAB. No entanto, na maioria dos cultivos da palma forrageira têm sido dispensadas, à região, maiores preocupações em manejos e tratos culturais básicos. Em outras palavras, a palma forrageira nunca foi encarada como lavoura. Entretanto e de acordo com Moura et al. (2011) a palma forrageira, tal como outra cultura qualquer, não dispensa tratos culturais básicos, tais como fertilização, controle de plantas daninhas, doenças e pragas, como a cochonilha de escama (Pinnaspis aspidistrae) e a cochonilha-do-carmim (Dactylopius opuntiae) além do delineamento de densidade de plantio adequado para expressar seu potencial produtivo. Neste contexto, o conhecimento das condições climáticas específicas subsidia em informações para maximização da produção da palma forrageira. Assim, a realização do zoneamento agroclimático visa obter maiores informações sobre a adaptabilidade das culturas selecionadas e, sobretudo, proporcionar maior retorno dos investimentos a médio e longo prazos para os produtores contribuindo, desta forma, para uma agricultura racional e sustentável (Nunes et al., 2007; Possas et al., 2012). O zoneamento de aptidão climática é uma ferramenta de extrema importância e amplamente utilizada no planejamento do calendário agrícola, na definição das linhas de financiamento rural e na avaliação de impactos climáticos sobre o rendimento das culturas. Por essas razões, o zoneamento agroclimático de várias culturas tais como café, cana-de-açúcar, algodão e laranja, dentre outras, tem sido feito para diferentes regiões brasileiras (Assad et al., 2013; Nunes et al., 2007; Silva et al., 2009; Medeiros et al., 2009; Possas et al., 2012).

Embora se tenha referência, na literatura, sobre as condições climáticas favoráveis ao cultivo da palma forrageira por se tratar de uma cultura com grandes oportunidades de adaptabilidade às condições de semiaridez, seu cultivo tem sido realizado sem que haja um embasamento técnico-científico no que concerne às suas necessidades climáticas (Moura et al., 2011). Diante do exposto o presente trabalho tem, como objetivo, determinar o zoneamento da aptidão climática da palma forrageira (Opuntia sp.) que engloba as cultivares vulgarmente conhecidas como gigante, orelha-de-elefante e orelha-de-onça, para o estado da Paraíba.

\section{Material e Métodos}

O estado da Paraíba está localizado na Região Nordeste do Brasil, limitado pelos estados de Pernambuco (ao sul), Ceará (a oeste), Rio Grande do Norte (ao norte) e pelo Oceano Atlântico (a leste). É subdividido em quatro mesorregiões: Litoral Paraibano, Agreste Paraibano, Borborema e Sertão Paraibano (Figura 1).

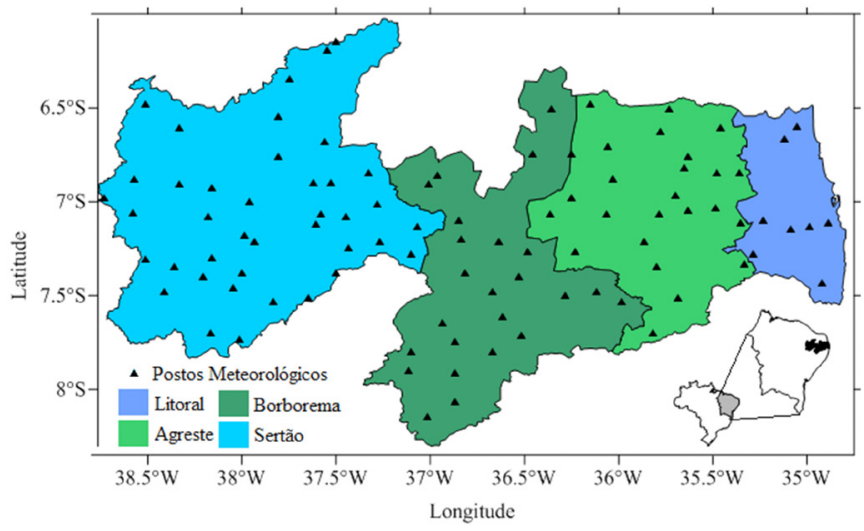

Figura 1. Distribuição espacial dos postos meteorológicos do estado da Paraíba cujos dados foram utilizados na elaboração do zoneamento agroclimático da palma forrageira

Para a elaboração do zoneamento agroclimático da palma forrageira foram utilizados os dados climatológicos de 97 postos meteorológicos do estado da Paraíba, bem distribuídos espacialmente, contemplando todas as mesorregiões do estado, conforme o mapa apresentado na Figura 1. Os dados climáticos mencionados correspondem aos valores mensais e anuais da temperatura (média, máxima e mínima) e aos totais mensais e anuais da precipitação, disponíveis na página virtual da Unidade Acadêmica de Ciências Atmosféricas (UACA) da Universidade Federal de Campina Grande (UFCG).

Para as localidades que dispunham apenas dos registros da precipitação, os valores da temperatura do ar foram estimados em função das coordenadas geográficas locais (latitude $(\varphi$, em grau decimal); longitude ( $\lambda$, em grau decimal) e altitude (h, em m)) utilizando-se o modelo proposto por Cavalcanti \& Silva (1994) (Eq. 1). De acordo com Cavalcanti et al. (2006), nas regiões tropicais, em que a precipitação pluvial é bastante variável no tempo, no espaço, na duração e na quantidade, a temperatura do ar apresenta baixa variabilidade, portanto facilmente modelada em função das coordenadas geográficas. O modelo desenvolvido por Cavalcanti \& Silva (1994) (Eq. 1) tem apresentado desempenho satisfatório, além de amplamente utilizado (Silva et al., 2006; Medeiros et al., 2009; Moura et al., 2011).

$\mathrm{T}=\mathrm{c}_{0}+\mathrm{c}_{1} \lambda+\mathrm{c}_{2} \varphi+\mathrm{c}_{3} \mathrm{~h}+\mathrm{c}_{4} \lambda^{2}+\mathrm{c}_{5} \varphi^{2}+\mathrm{c}_{6} \mathrm{~h}^{2}+\mathrm{c}_{7} \lambda \varphi+\mathrm{c}_{8} \lambda \mathrm{h}+\mathrm{c}_{9} \varphi \mathrm{h}$

em que: $c_{0}, c_{1}, c_{2}, c_{3}, c_{4}, c_{5}, c_{6}, c_{7}, c_{8}$ e $c_{9}$ são os coeficientes da função quadrática obtidos a partir da regressão dos quadrados mínimos. 
Os indicadores climáticos da palma forrageira utilizados no presente estudo foram estabelecidos por Souza et al. (2008) os quais estão apresentados na Tabela 1. Esses dados também foram utilizados por Moura et al. (2011) na elaboração do zoneamento agroclimático da palma forrageira para o estado de Pernambuco.

Para a elaboração do zoneamento agroclimático da palma forrageira, foi montado um banco de dados contendo a temperatura (média, máxima e mínima), a amplitude térmica e a precipitação de todos os 97 postos meteorológicos do estado da Paraíba. O referido banco de dados ainda foi complementado com os dados do índice de umidade no solo (Iu) de cada posto meteorológico obtidos mediante o cálculo do balanço hídrico climatológico utilizando-se o modelo proposto por Thornthwaite (1948) o qual pode ser encontrado detalhadamente descrito em Ayoade (2012). O índice de umidade foi calculado com base nos índices de aridez e hídrico, conforme as equações seguintes:

$$
\begin{gathered}
\mathrm{Ia}=\frac{(100 \times \mathrm{DEF})}{\mathrm{ET}_{\mathrm{P}}} \\
\mathrm{Ih}=\frac{(100 \times \mathrm{EXC})}{\mathrm{ET}_{\mathrm{P}}} \\
\mathrm{Iu}=\mathrm{Ih}-0,6 . \mathrm{Ia}
\end{gathered}
$$

em que:

$$
\begin{aligned}
& \text { Ia - índice de aridez } \\
& \text { DEF - déficit hídrico } \\
& \mathrm{ET}_{\mathrm{P}} \text { - evapotranspiração potencial } \\
& \mathrm{Ih} \text { - índice hídrico } \\
& \mathrm{EXC} \text { - excedente hídrico } \\
& \mathrm{Iu} \text { - índice de umidade }
\end{aligned}
$$

O zoneamento agroclimático da palma forrageira foi obtido para cada um dos indicadores climáticos apresentados na Tabela 1 e para cada um dos postos meteorológicos do estado da Paraíba. Posteriormente, as informações do zoneamento resultante de cada indicador e de cada posto meteorológico foram cruzadas para, enfim, obter-se o zoneamento final, adotando os seguintes critérios em conformidade com Moura et al. (2011):

- Aptidão plena: Região na qual os índices climáticos não apresentaram restrição alguma ao cultivo da palma;
- Aptidão com restrições: Região na qual pelo menos um dos indicadores climáticos estudados apresenta restrição ao desenvolvimento da palma forrageira;

- Inapta: Região na qual pelo menos um dos indicadores climáticos é limitante ao cultivo da palma-forrageira.

A partir dos critérios acima descritos obteve-se um mapa de classes de aptidão climática. O método de interpolação utilizado para confecção do mapa foi "krigagem ordinária".

A precipitação média climatológica do estado da Paraíba é predominantemente inferior a $1000 \mathrm{~mm}$ (Figura 2A). $\mathrm{Na}$ região central do estado, mesorregião da Borborema, é onde se registram os menores volumes de chuva, predominantemente em torno de $500 \mathrm{~mm}$; já na parte oeste do estado, mesorregião do Sertão, a precipitação média é predominantemente superior a $800 \mathrm{~mm}$. Os maiores volumes de chuva são registrados na parte leste do estado, ou seja, na mesorregião do Litoral, onde os volumes médios ultrapassam valores de $1200 \mathrm{~mm}$. Outras regiões que apresentam este padrão de precipitação são a região do Brejo de altitude de Areia, no Agreste, e o município de Olho d’Água, no Sertão Paraibano.

Quanto à temperatura, os valores médios climatológicos mais elevados das temperaturas média, máxima e mínima ocorrem na mesorregião do Litoral e Sertão Paraibano (Figuras $2 \mathrm{~B}, \mathrm{C}$ e $\mathrm{D}$, respectivamente). As temperaturas amenas são registradas na mesorregião da Borborema e na mesorregião

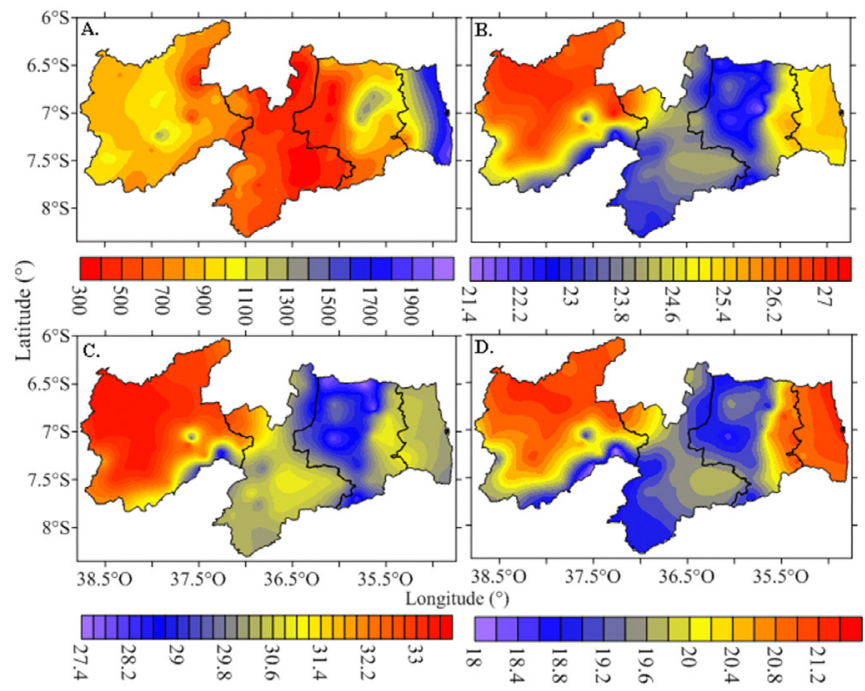

Figura 2. Dados climatológicos de (A) Precipitação $(\mathrm{mm}),(\mathrm{B})$ Temperatura média $\left({ }^{\circ} \mathrm{C}\right),(\mathrm{C})$ Temperatura máxima $\left({ }^{\circ} \mathrm{C}\right)$ e $(\mathrm{D})$ Temperatura mínima $\left({ }^{\circ} \mathrm{C}\right)$

Tabela 1. Indicadores climáticos utilizados na elaboração do zoneamento agroclimático da palma forrageira para o estado da Paraíba

\begin{tabular}{lccc}
\hline Parâmetro climático & \multicolumn{1}{c}{ Aptidão } & Com restrições & Inapta \\
\cline { 2 - 4 } Temperatura média $\left({ }^{\circ} \mathrm{C}\right)$ & Plena & Tmed $<16,1$ e Tmed $>25,4$ & - \\
Temperatura máxima $\left({ }^{\circ} \mathrm{C}\right)$ & $16,1 \leq \mathrm{Tmed} \leq 25,4$ & Tmax $<28,5$ e Tmax 31,5 & - \\
Temperatura mínima $\left({ }^{\circ} \mathrm{C}\right)$ & $28,5 \leq \mathrm{Tmax} \leq 31,5$ & $\mathrm{Tmin}<8,6$ e Tmin $>20,4$ & - \\
Amplitude térmica $\left({ }^{\circ} \mathrm{C}\right)$ & $8,6 \leq \mathrm{Tmin} \leq 20,4$ & $\Delta \mathrm{T}<10,0$ e $\Delta \mathrm{T}>17,2$ & - \\
Precipitação $(\mathrm{mm})$ & $10,0 \leq \Delta \mathrm{T} \leq 17,2$ & $812,4 \leq \mathrm{P} \leq 1089,9$ e $\mathrm{P}<368,4$ & $\mathrm{P}>1089,9$ \\
Índice de umidade $(-)$ & $368,4 \leq \mathrm{P} \leq 812,4$ & $-31,8 \leq \mathrm{P} \leq-7,7$ e lu $<-65,6$ & lu $>7,7$ \\
\hline
\end{tabular}

Fonte: Souza et al. (2008) 
do Agreste. Este fato está relacionado ao fator altitude, visto que as referidas regiões estão localizadas sobre o Planalto da Borborema, onde também estão localizadas as maiores altitudes do estado da Paraíba.

\section{Resultados e Discussão}

A Figura 3 apresenta o mapa do zoneamento de aptidão climática da cultura da palma forrageira (Opuntia sp.) para o Estado da Paraíba. Constata-se, de acordo com o referido mapa, que a mesorregião da Borborema é a que propicia as melhores condições climáticas para o cultivo desta cactácea. As únicas restrições para o cultivo da palma forrageira na mesorregião da Borborema quanto à precipitação nas regiões polarizadas por Cabaceiras, Caraúbas e Picuí, cujas médias climatológicas são inferiores a $368 \mathrm{~mm}$ (Figura 2A), o limite inferior da aptidão plena. Outra restrição ocorre no noroeste da mesorregião, em torno do município de São Mamede, a qual está relacionada às temperaturas média, máxima e mínima, cujos valores médios climatológicos são superiores ao limite superior da aptidão plena, conforme apresenta as Figuras 2B, $2 \mathrm{C}$ e $2 \mathrm{D}$, respectivamente.

Além do padrão de precipitação predominante da mesorregião da Borborema estar dentro da faixa de aptidão plena para o cultivo da palma forrageira, outros fatores climáticos também convergem para esta condição, tais como temperatura máxima que varia, predominantemente de 27 a 30 ${ }^{\circ} \mathrm{C}$, a temperatura média que varia, predominantemente de 20 a $25^{\circ} \mathrm{C}$ e a temperatura mínima que varia, predominantemente, de 18 a $20{ }^{\circ} \mathrm{C}$ (Figura 2B, 2C e 2D). Também favorecem o cultivo da palma forrageira na mesorregião da Borborema a amplitude térmica anual (Figura $4 \mathrm{~A}$ ) que varia de 11 a $12^{\circ} \mathrm{C}$ e o Índice de Umidade (Figura 4B) que oscila de -30 a -50. A faixa de variação da amplitude térmica na região da Borborema é devida à ocorrência de temperaturas amenas durante a noite, o que favorece a absorção de $\mathrm{CO}_{2}$, que nas plantas de metabolismo tipo CAM, a exemplo da palma forrageira, ocorre predominantemente à noite (Nobel \& Hartsock, 1984). A variação de 11 a $12{ }^{\circ} \mathrm{C}$ é classificada como faixa de variação ótima de temperatura para as cactáceas (Nobel \& Hartsock, 1984; Nobel, 1994).

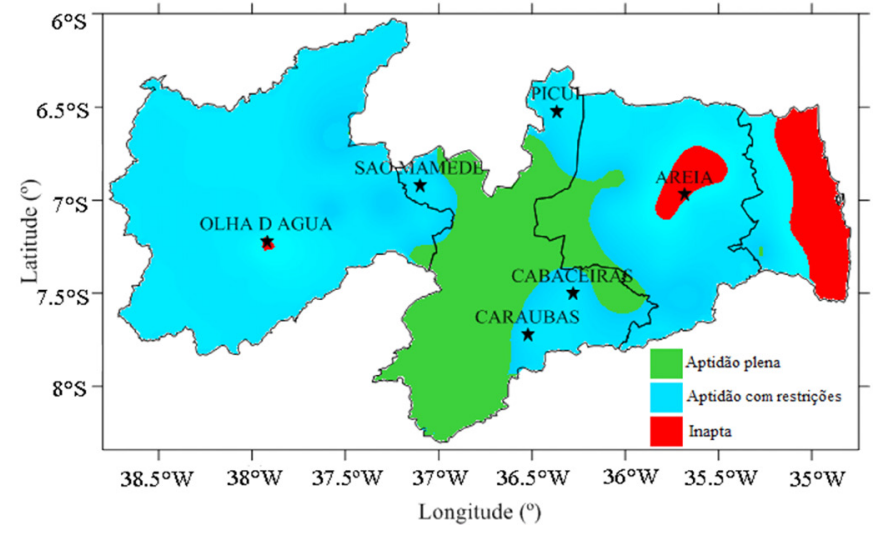

Figura 3. Aptidão climática da palma forrageira para o estado da Paraíba
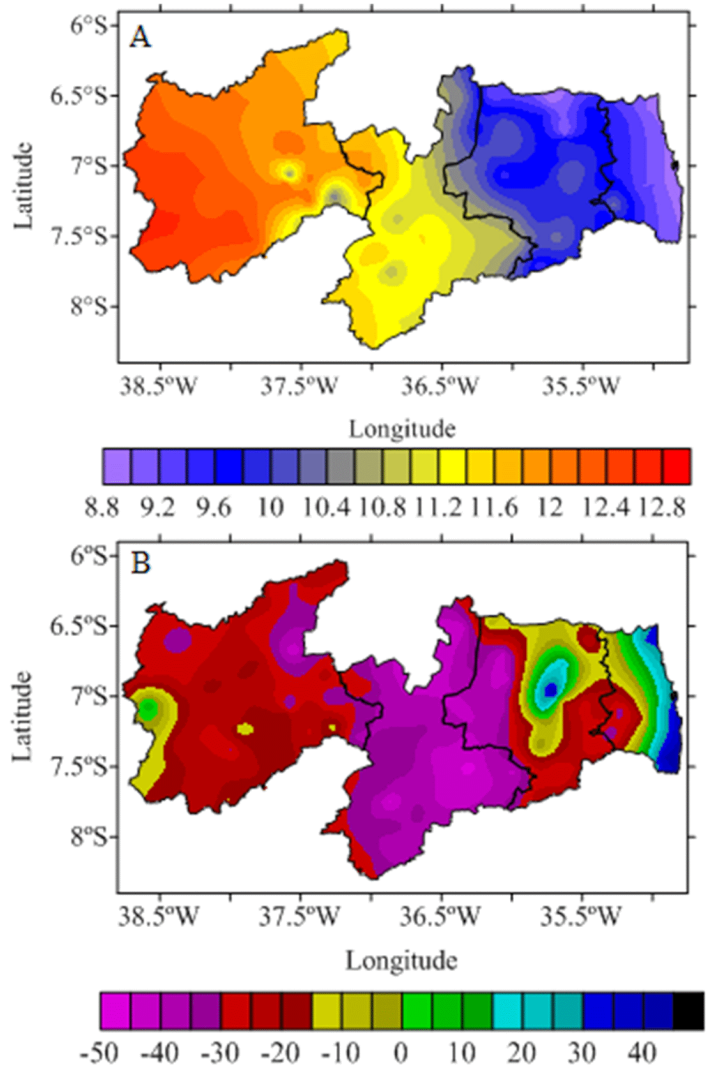

Figura 4. Distribuição espacial da amplitude térmica anual (A) e do índice de umidade (B) do Estado da Paraíba

A mesorregião do Sertão Paraibano é predominantemente apta com restrições para o cultivo da palma forrageira. Todos os indicadores bioclimáticos apresentam restrições nesta mesorregião, com exceção da amplitude térmica (Figura 4A). A precipitação média anual é, na maioria dos postos meteorológicos, superior a $812,4 \mathrm{~mm}$, o limiar entre a aptidão plena e a aptidão restrita (Tabela 1 ), a temperatura média é predominantemente superior a $25^{\circ} \mathrm{C}$, a temperatura máxima é predominantemente superior a $32{ }^{\circ} \mathrm{C}$ e a temperatura mínima é predominantemente superior a $20^{\circ} \mathrm{C}$ (Figuras $2 \mathrm{~A}, 2 \mathrm{~B}, 2 \mathrm{C}$ e 2D). Verifica-se ainda que o Iu varia predominantemente na faixa de restrição, ou seja, de -30 a -20 .

A restrição do cultivo da palma forrageira quanto às temperaturas elevadas, se deve ao fato da temperatura exercer grande influência no mecanismo de absorção de $\mathrm{CO}_{2}$. De acordo com Nobel \& Hartsock (1984) as porções de $\mathrm{CO}_{2}$ absorvido pelas cactáceas diminui consideravelmente à medida que a temperatura aumenta. De acordo Nobel (1994) isto ocorre porque as elevadas temperaturas inibem a abertura dos estômatos e a atividade das enzimas fotossintéticas. Por essas razões é nítida, de acordo com a literatura, a melhor produtividade da palma forrageira na região Nordeste em áreas de temperaturas amenas, a exemplo do Agreste de Pernambuco, conforme relato de Moura et al. (2011). No estado da Paraíba se constata que a produtividade da palma forrageira na região da Borborema chega a ser aproximadamente 68\% superior aos valores observados no Sertão (Lima, 2011; Sousa \& Sousa Neto, 2012). 
As áreas do estado da Paraíba inaptas ao cultivo da palma forrageira são a parte leste que tangencia o litoral na mesorregião do Litoral Paraibano, o brejo de altitude de Areia, no Agreste Paraibano e uma pequena área em torno do município de Olho d’Água, no Sertão Paraibano.

As fontes de inaptidão agroclimática ao cultivo da palma forrageira da parte costeira do Litoral Paraibano são a precipitação, que é predominantemente superior a $1500 \mathrm{~mm}$ (Figura 2A) e o Iu, que é predominantemente superior a 10 (Figura 4B). Na região do Brejo Paraibano, polarizada pelo município de Areia, a exemplo da faixa costeira do Litoral Paraibano, a inaptidão climática para o cultivo da palma forrageira também se dá em função da precipitação superior a $1100 \mathrm{~mm}$ (Figura 2A) e do Iu superior a 15 (Figura 4B). Por outro lado, a inaptidão climática na região, em torno de Olho d’Água no Sertão Paraibano, é função apenas da precipitação cuja média climatológica é igual a $1512 \mathrm{~mm}$. O Iu, por sua vez, é da ordem de -5 (Figura 4B).

Em condições de elevada quantidade de água no solo a palma forrageira tem seu desenvolvimento inibido visto que as plantas CAM são fisiologicamente preparadas para as condições de escassez de água em virtude de desenvolverem mecanismos de armazenamento de quantidades consideráveis de água em seus tecidos, bem como fixam $\mathrm{CO}_{2}$ durante a noite reduzindo a transpiração devez que a perda de água à noite é mais baixa que durante o dia (Nobel, 1994; Snyman, 2006b). Assim, sob condições de umidade abundante no solo acumulam água em quantidades superiores à sua capacidade transpirativa e ensejam a ocorrência do apodrecimento, tombamento e só então se tornam altamente vulneráveis a doenças, principalmente àquelas causadas por fungos.

A mesorregião do Agreste, por sua vez, é a única que apresenta as três classes de aptidão climática ao cultivo da palma forrageira: plena na parte oeste, inapta no Brejo de altitude em torno de Areia, conforme já discutido e com restrições no restante da área. Isto ocorre dado ao motivo fato desta mesorregião apresentar um padrão climático bastante heterogêneo em relação às demais mesorregiões. Tal heterogeneidade ocorre devido a mesorregião do Agreste ser uma faixa de transição entre o Litoral, região úmida (maiores volumes de precipitação (Figura 2A) e manutenção da umidade no solo durante $\mathrm{o}$ ano inteiro, na maior parte das áreas (Figura 4B) e a Borborema, região mais seca do estado, pois apresenta os mais baixos volumes pluviométricos (Figura $2 \mathrm{~A}$ ) e as condições de déficit hídrico mais severas (Figura 4B).

A heterogeneidade climática da mesorregião do Agreste é evidenciada pelo padrão de distribuição espacial da precipitação
(Figura 2A). De acordo com a Tabela 2, a precipitação média é de $789 \mathrm{~mm}$ porém com desvio padrão de $328 \mathrm{~mm}$. Os valores mínimo e máximo são 366 e 1367 mm registrados em Barra de Santa Rosa e Areia, respectivamente. Esta variabilidade confere um coeficiente de variação de $41,5 \%$, o maior entre as mesorregiões do estado.

A inaptidão e a aptidão restrita ao cultivo da palma forrageira quanto à precipitação são bastante dinâmicas na região, ou seja, caracterizadas pela elevada variabilidade temporal; entretanto, é possível que, durante uma sucessão de anos a aptidão agroclimática da palma forrageira de determinada área ou região, varie entre plena, restrita ou até inapta, quanto ao volume precipitado, tomando-se o exemplo de Cabaceiras, que apresenta aptidão restrita devido à precipitação média climatológica de $316,6 \mathrm{~mm}$, inferior ao limite mínimo da aptidão plena. No entanto, o desvio padrão da precipitação em Cabaceiras é de 187,1 mm significando que, climatologicamente, a precipitação esperada varia de 129.5 a 503,7 mm. Assim, em uma sucessão de anos em que a precipitação acumulada anual for acima da média e esteja dentro da variabilidade climatológica esperada (média mais o desvio padrão) torna Cabaceiras uma área plenamente apta. O mesmo raciocínio também é aplicado para Brejo do Cruz, na mesorregião do Sertão Paraibano cuja precipitação média anual é de $820,8 \mathrm{~mm}$, acima do limite máximo da aptidão plena, 812,4 mm conforme Souza et al. (2008), (Tabela 1); apesar disto, apresenta um desvio padrão de $317,2 \mathrm{~mm}$; desta forma, em anos muito chuvosos e anos com precipitação abaixo da média, esta localidade tem sua aptidão variando de plena a inapta.

Por outro lado, a restrição ao cultivo da palma forrageira relacionada à temperatura é mais estável interanualmente que as restrições relacionadas à precipitação, visto que as variações sazonais da temperatura nas regiões tropicais, a exemplo do estado da Paraíba, são muito pequenas em comparação com outras variáveis atmosféricas, tais como umidade e precipitação (Cavalcanti et al., 2006; Ayoade, 2012). De acordo com Ayoade (2012) as variações sazonais da temperatura resultam sobretudo da variação sazonal da insolação que, por sua vez, é muito baixa nas regiões tropicais, durante o ano.

No entanto, essas restrições não inviabilizam o cultivo da palma forrageira mas se expressarão em eventuais quedas de rendimento de matéria seca, deficiências na assimilação de alguns nutrientes, entre outros.

A Figura 5 apresenta a distribuição espacial das zonas de aptidão climática para a palma forrageira por municípios.

Tabela 2. Precipitação (média, mínima e máxima), desvio padrão (DP) e coeficiente de Variação (CV) das mesorregiões do estado da Paraíba

\begin{tabular}{|c|c|c|c|c|}
\hline \multirow{2}{*}{ Mesorregião } & \multicolumn{3}{|c|}{ Precipitação (mm) } & \multirow{2}{*}{$\begin{array}{l}\text { CV } \\
\text { (\%) }\end{array}$} \\
\hline & Média \pm DP & Máxima (Posto) & Mínima (Posto) & \\
\hline Litoral Paraibano & $1384 \pm 343$ & 1867 (Alhandra) & 781 (Itabaiana) & 27,8 \\
\hline Agreste Paraibano & $789 \pm 328$ & 1367 (Areia) & 366 (Barra de Santa Rosa) & 41,5 \\
\hline Borborema & $534 \pm 129$ & 789 (Sumé) & 316 (Cabaceiras) & 24,1 \\
\hline Sertão Paraibano & $839 \pm 153$ & 1512 (Olho d'Água) & 397 (Vista Serrana) & 18,3 \\
\hline
\end{tabular}




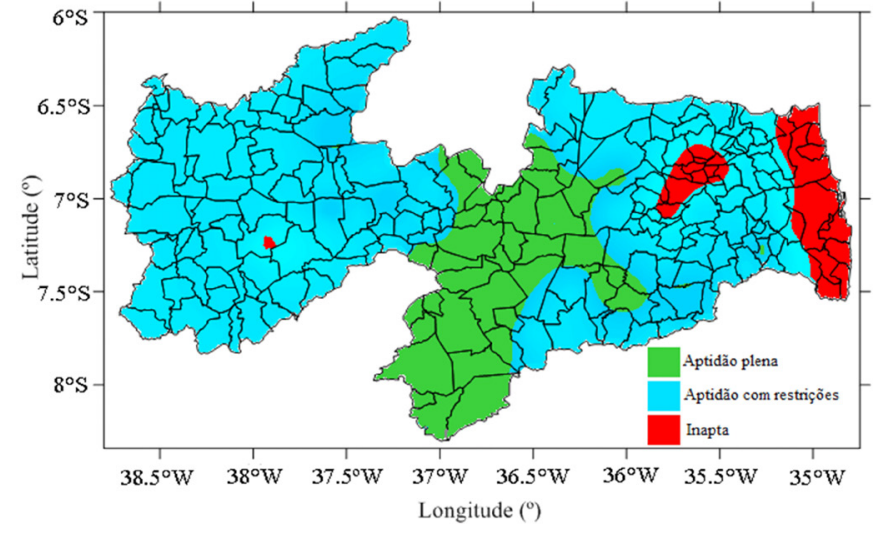

Figura 5. Aptidão climática da palma forrageira para o estado da Paraíba, distribuída por município

\section{Conclusões}

1. A mesorregião da Borborema e a parte centro-ocidental da mesorregião do Agreste Paraibano são as áreas que apresentam as condições climáticas mais favoráveis para o cultivo da palma forrageira (Opuntia sp.) no estado da Paraíba.

2. A mesorregião do Litoral Paraibano apresenta as condições climáticas mais desfavoráveis para o cultivo da palma forrageira no estado da Paraíba.

3. O cultivo da palma forrageira pode ser realizado em todo o território do estado da Paraíba, exceto na zona costeira da mesorregião do Litoral Paraibano e no brejo de altitude em torno do município de Areia, no Agreste Paraibano.

4. A mesorregião do Agreste Paraibano e a mesorregião do Sertão Paraibano apresentam restrições quanto à precipitação e/ou à temperatura.

\section{Literatura Citada}

Araújo, L. F.; Medeiros, A. N.; Perazzo Neto, A.; Oliveira, L. S. C.; Silva, F. L. H. da. Protein enrichment of cactus pear (Opuntia ficus - indica Mill) using Saccharomyces cerevisiae in solid-state fermentation. Brazilian Archives of Biology and Technology, v.48, p.161-168, 2005.

Assad, E. D.; Martins, S. M.; Beltrão, N. E. de M.; Pinto, H.

S. Impacts of climate change on the agricultural zoning of climate risk for cotton cultivation in Brazil. Pesquisa Agropecuária Brasileira, v.48, p.1-8, 2013.

Ayoade, J. O. Introdução à climatologia para os trópicos. 16. ed. Rio de Janeiro: Bertrand Brasil, 2012. 332p.

Cardador-Martínez, A.; Jiménez-Martínez, C.; Sandoval, G. Revalorization of cactus pear (Opuntia ssp.) wastes as a sources of antioxidants. Ciência e Tecnologia de Alimentos, v.31, p.782-788, 2011.

Cavalcanti, E. P.; Silva, E. D. V. Estimativa da temperatura do ar em função das coordenadas locais. In: Congresso Brasileiro de Meteorologia, 8, e Congresso Latino-Americano e Ibérico de Meteorologia, 2, 1994, Belo Horizonte. Anais... Belo Horizonte: SBMET, 1994. p.154-157.
Cavalcanti, E. P.; Silva, V. de P. R. da; Sousa, F. de A. S. Programa computacional para a estimativa da temperatura do ar para a Região Nordeste do Brasil. Revista Brasileira de Engenharia Agrícola e Ambiental, v.10, p.140-147, 2006.

Felker, P.; Rodriguez, S. C.; Casoliba, R. M.; Filippini, R.; Medina, D.; Zapata, R. Comparison of Opuntia fícus-indica varieties of Mexican and Agentine origin for fruit yield and quality in Argentina. Journal of Arid Environments, v.60, p.405422, 2005.

Gentile, C.; Tesoriere, L.; Allegra, M.; Livrea, M. A.; D’Alessio, P. Antioxidant betalains from cactus pear (Opuntia ficusindica) inhibit endothelial ICAM-1 expression. Annals of the New York Academy of Sciences, v.1028, p.481-486, 2004.

Lima, P. F. U. Sistema de cultivo adensado da palma forrageira sob adubação organo-mineral. Patos: UFCG, 2011. 46p. Dissertação Mestrado

Medeiros, S. R. R.; Moura, G. B. A.; Giongo, P. R.; Silva, A. P. N. Potencial agroclimático para a Alpinia purpurata, no Estado de Pernambuco. Revista Brasileira de Engenharia Agrícola e Ambiental, v.13, p.165-169, 2009.

Moura, M. S. B.; Souza, L. S. B.; Silva, T. G. F.; Sá, I. I. S. Zoneamento agroclimático da palma forrageira para o estado de Pernambuco. Petrolina: Embrapa Semiárido 2011. 26p. Documentos 242.

Nobel, P. S. Remarkable agaves and cacti. New York: Oxford University Press, 1994. 116p.

Nobel, P. S.; Hartsock, T. L. Physiological responses of Opuntia ficus-indica to growth temperature. Physiologia Plantarum, v.60, p.98-105, 1984.

Nunes, E. L.; Amorim, R. C. F.; Souza, W. G.; Ribeiro, A.; Senna, M. C. A.; Leal, B. G. Zoneamento agroclimático da cultura do café para a Bacia do Rio Doce. Revista Brasileira de Meteorologia, v.22, p.297-302, 2007.

Pinto, T. F.; Costa, R. G.; Medeiros, A. N. de; Medeiros, G. R.; Azevedo, P. S.; Oliveira, R. L.; Treviño, I. H. Use of cactus pear (Opuntia ficus indica Mill) replacing corn on carcass characteristics and non-carcass components in Santa Inês lambs. Revista Brasileira de Zootecnia, v.40, p.1333-1338, 2011.

Possas, J. M. C.; Correa, M. M.; Moura, G. B. A.; Lopes, P. M. O.; Caldas, A. M.; Fontes Júnior, R. V. P. Zoneamento agroclimático para a cultura do pinhão-manso no Estado de Pernambuco. Revista Brasileira de Engenharia Agrícola e Ambiental, v.16, p.993-998, 2012.

Reyes-Agüero, J. A.; Aguirre, J. R.; Valiente-Banuet, R. A. Reproductive biology of Opuntia: A review. Journal of Arid Environments, v.64, p.549-585, 2006.

Santos, D. C.; Farias, I.; Lira, M. A.; Santos, M. V. F.; Arruda, G. P.; Coelho, R. S. B.; Dias, F. M.; Melo, J. N. Manejo e utilização da palma forrageira (Opuntia e Nopalea) em Pernambuco. Recife: Empresa Pernambucana de Pesquisa Agropecuária. 2006. 48p. Documentos 30

Santos, D. C.; Santos, M. V. F.; Farias, I.; Dias, F. M.; Lira, M. A. Desempenho produtivo de vacas 5/8 Holando/Zebu alimentadas com diferentes cultivares de palma forrageira (Opuntia e Nopalea). Revista Brasileira de Zootecnia, v.30, p.12-17, 2001. 
Silva, T. G. F.; Zolnier, S.; Moura, M. S. B.; Sediyama, G. C. Potencial pedoclimático do estado da Bahia para o cultivo da atemóia. Revista Brasileira de Engenharia Agrícola e Ambiental, v.13, p.566-574, 2009.

Silva, V. de P. R. da; Sousa, F. de A. S.; Cavalcanti, E. P.; Souza, E. P.; Silva, B. B. Teleconnections between sea-surface temperature anomalies and air temperature in northeast Brazil. Journal of Atmospheric and Solar-Terrestrial Physics, v.68, p.781-792, 2006.

Snyman, H. A. Root distribution with changes in distance and depth of two-year-old cactus pears Opuntia ficus-indica and O. robusta plants. South African Journal of Botany, v.72, p.434-441, 2006a.

Snyman, H. A. A greenhouse study on root dynamics of cactus pears, Opuntia ficus-indica and O. robusta. Journal of Arid Environments, v.65, p.529-542, 2006b.

Sousa, T. P.; Sousa Neto E. P. Produção da palma forrageira (Opuntia ficus-indica Mill. e Nopalea cocherilifera SalmDyck) como alternativa de alimentação para criações no Semi-Árido. In: Simpósio Brasileiro de Captação e Manejo de Água de Chuva, 8, 2012. Campina Grande. Anais... Campina Grande: ABCMAC. 2012. CD-Rom
Souza, L. S. B.; Moura, M. S. B.; Silva, T. G. F.; Soares, J. M.; Carmo, J. F. A.; Brandão, E. O. Indicadores climáticos para o zoneamento agrícola da palma forrageira (Opuntia sp.). In: Jornada de Iniciação Científica da Embrapa Semiárido, 3, 2008, Petrolina. Anais..Petrolina: Embrapa Semi-Árido, 2008. p.23-28. Documentos 210

Taiz, L.; Zeiger, E. Fisiologia vegetal. 3.ed. Porto Alegre: ARTMED, 2004. 719p.

Tesoriere, L.; Butera, D.; Pintaudi, A. M.; Allegra, M.; Livrea, M. 2004. Supplementation with cactus pear (Opuntia ficusindica) fruit decreases oxidative stress in healthy humans: a comparative study with vitamin C. American Journal of Clinical Nutrition, v.80, p.391-395, 2004.

Thornthwaite, C. W. An approach toward a rational classification of climate. Geographical Review, v.38, p.55-94, 1948.

Yahia, E.; Mondragon-Jacobo, C. Nutritional components and anti-oxidant capacity of ten cultivars and lines of cactus pear fruit (Opuntia ssp.). Food Research International, v.44, p.2311-2318, 2011. 